\title{
Study of deformation properties of road foundations of the mixed type intended for the movement of mobile complexes for monitoring and transporting raw materials
}

\author{
Alexander Belyaev ${ }^{1}$, Alina Markovnina ${ }^{1}$, Vladimir Belyakov ${ }^{1}$, Vladimir Makarov ${ }^{1,2 *}$, \\ ${ }^{1}$ Nizhny Novgorod State Technical University n.a. R.E. Alekseev, 603950, Minina str., 24, Nizhny Novgorod, Russia \\ 2 Bauman Moscow State Technical University, 105005, $2^{\text {th }}$ Baumanskaya str., 5/1, Moscow, Russia
}

\begin{abstract}
Analysis of the conditions of movement of mobile robotic complexes showed that about $70 \%$ of the time of movement is made up of sand, gravel and sandy areas. In winter, it is covered with snow. An unsolved problem is the traffic conditions during the transition period, namely, movement on snow-sandy support bases. This paper is devoted to the study of road and soil foundations, i.e. mixed surfaces consisting of sand and snow. A method for obtaining mixed surfaces (mixtures) with different percentages is described. It is shown how the measurements of the density and fractional composition of the sand were carried out. It also shows how the snow density was measured. Examples of test fragments are given. A test procedure for measurement of deformation properties is presented. "Load-deformation" curves are provided. The study reveals how the sand and snow percentage affects the curve behaviour. Dependencies are given to describe the process "load - deformation" for sand and snow. The dependence of the mixtures is proposed. The generalized dependence includes the dependences of Goryachkin - Letoshnev and Malygin. This paper also specifies the curve behaviour for an undisturbed road and soil foundation, and a surface exposed to an operating mover or a utility vehicle. It is shown that for mixtures of various compositions for an intact surface and under repeated loading, the difference in stresses is from 1.25 to 5 times.
\end{abstract}

\section{Introduction}

A previous study devoted to the motion and operating conditions of mobile robotic complexes (MRC) (Figures 1,2 ) in coastal zones [1-7] revealed typical support surfaces, or foundations [8, 9]. According to the research, around $70 \%$ of coastal zone foundations are sand-gravel and sandy soils. In winter, MRC travels on snow.

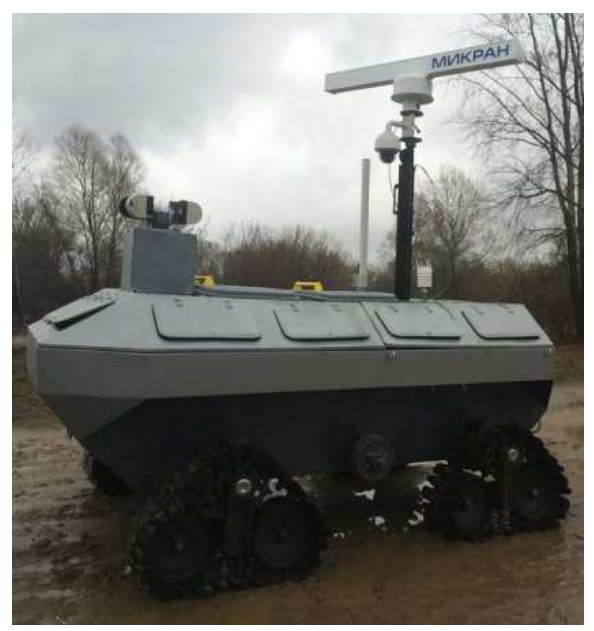

Fig. 1. Mobile robotic complexes with the caterpillar-modular mover



Fig. 2. Mobile robotic complexes with the wheel mover

A comprehensive study of special chassis can be found in the works of Nizhny Novgorod Scientific and Practical School of Transport Snow Science. It is yet unclear how MRC mobility is affected in spring, when support surfaces turn into mineral and icy disperse mixtures with layered structure. To be more specific, first chassis comes into contact with an undisturbed support surface, and then the mover interacts with the damaged surface. There are only few scientific papers presenting mixed surfaces as a mixture of soil and snow. Thus, it is important to address this issue in detail.

\footnotetext{
* Corresponding author: makvl2010@gmail.com
} 


\section{Analysis of approaches to solving the problem}

Different authors define mixed surfaces in different ways. The simplest definition is a combination of homogeneous areas with different physical and mechanical properties. Such approach is widely used in software simulations $[10,11]$. A mixed surface is defined as a combination of «squares» with different traction and resistance properties. See Figure 3.

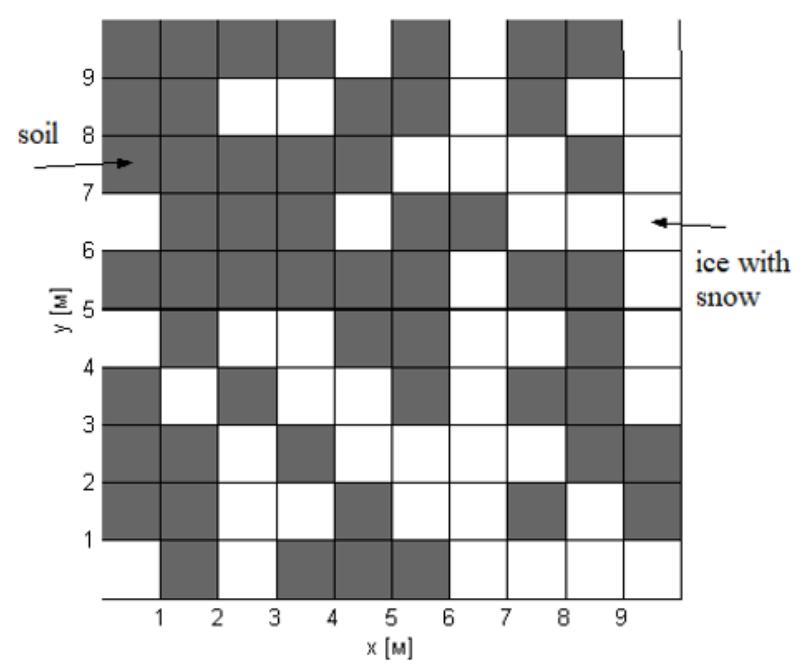

Fig. 3. Support surface as a combination of «squares» with different traction and resistance properties.

The most justified approach is presented in articles of Professor V.V. Belyakov, which define a mixed surface exactly as a mixture of sand and snow in different proportions, and include load-deformation curves. An example is displayed in Figure 4.

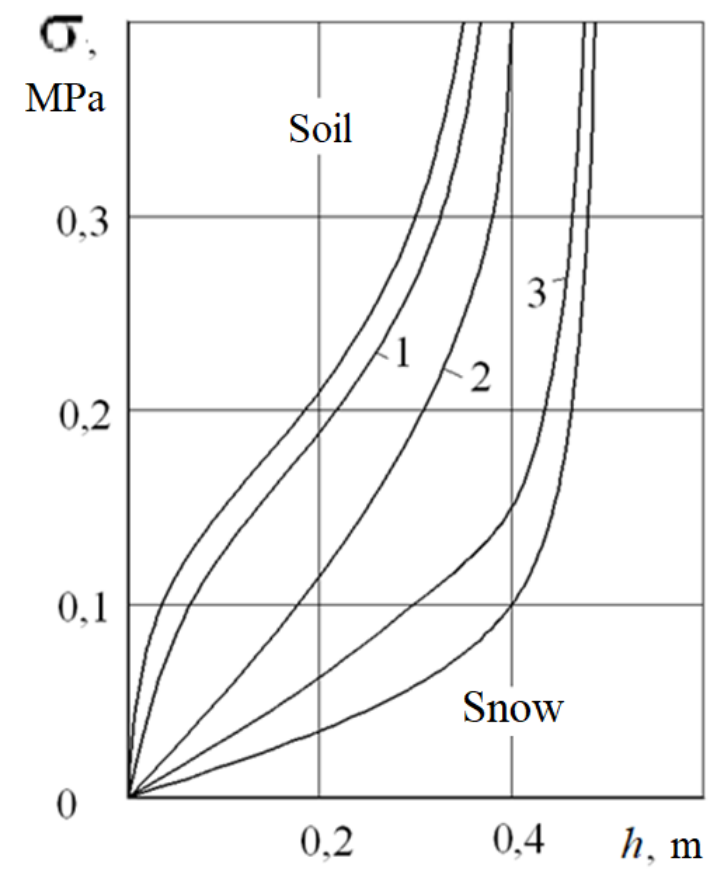

Fig. 4. Load-deformation diagram for mineral and snow mixed surfaces with $1 \quad 0,1 ; 2 \quad 0,5 ; 3 \quad 0,9$ concentration ratios.

\section{Experimental research}

The object of the study was sand with the average density of $1.36 \mathrm{~g} / \mathrm{cm}^{2}$ and snow with the average density of $0.37 \mathrm{~g} / \mathrm{cm}^{2}$.

The density of sand was determined by weighing dimensional samples, similar to the method from [9]. The fractional composition of the sand was also determined by sieving through sieves of different sizes. A fragment of the measurement is shown in Figure 5.



Fig. 5. Sifting sand through sieves of different sizes.

Table 1 shows the fractional composition of sand.

Table 1. Fractional composition of sand.

\begin{tabular}{|c|c|}
\hline Sand size, $\mathbf{m m}$ & $\begin{array}{c}\text { Relative percentage by weight } \\
\text { in the total volume, } \%\end{array}$ \\
\hline up to 2 & 3 \\
\hline from 2 to 1 & 12 \\
\hline from 1 to 0.75 & 62 \\
\hline from 0.75 to 0.25 & 18 \\
\hline from 0.25 to 0.1 & 1 \\
\hline less than 0.1 & \\
\hline
\end{tabular}

The density of snow for the preparation of mixtures was determined by weighing the measured volume of snow using a VS-43 device. A fragment of the measurement is shown in Figure 6. 


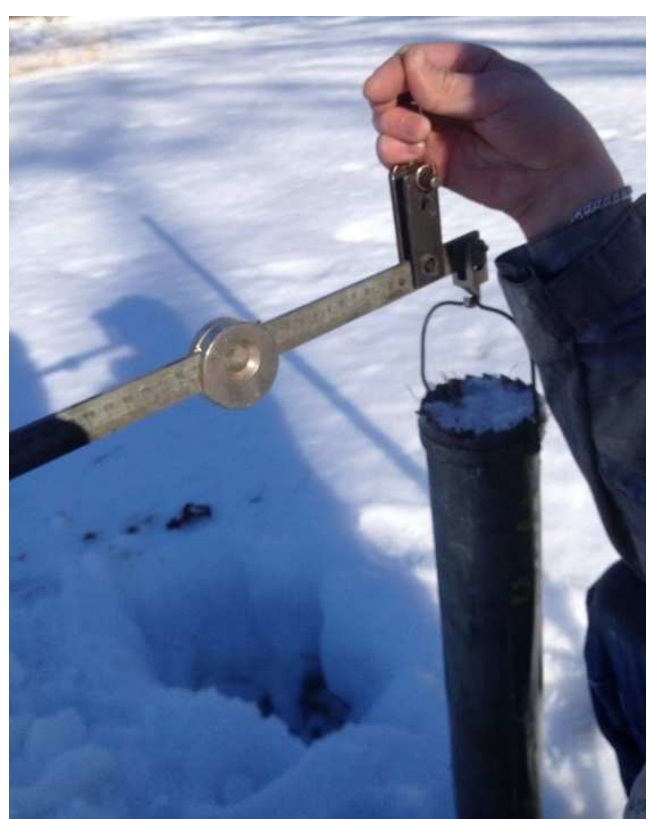

Fig. 6. Weighing the measured volume of snow using the VS43 device.

Mixing and measurement temperatures were set at a certain value to prevent the snow from melting. Special measuring jars were filled with sand-and-snow mixtures in the following proportions:

"Mixture - 0" - 100\% snow;

"Mixture - 25" - 75\% snow, 25\% sand;

"Mixture - 50" - 50\% snow, 50\% sand;

"Mixture - 75" - 25\% snow, 75\% sand;

"Mixture - 100" - 100\% sand.

Basically, "Mixture - 0" has only snow properties, and "Mixture - 100" has only sand properties. Figure 7 displays examples of measuring jars filled with mixtures.

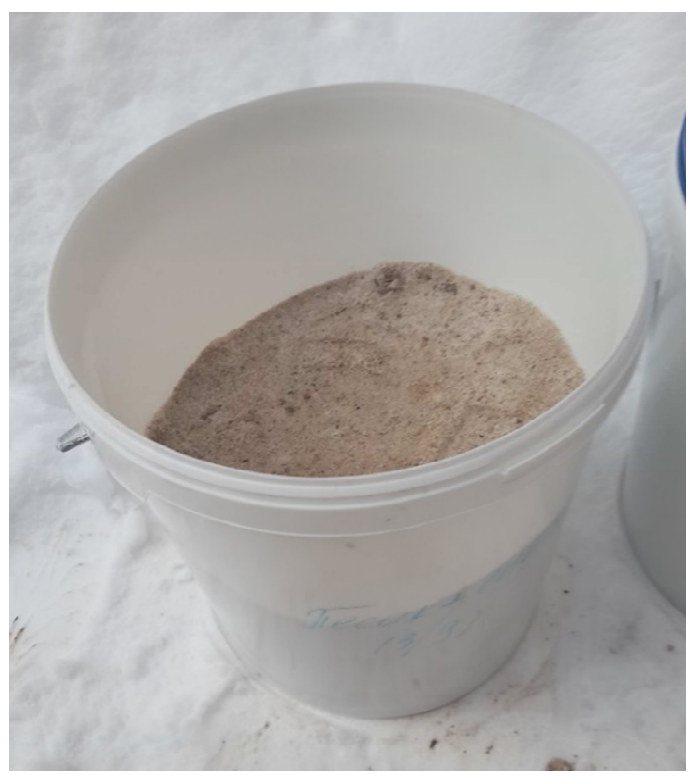

Fig. 7. Premade "Mixture-25".

Load-deformation properties were measured according to the scheme presented in Figure 8 . The numbers in the scheme: 1 - loader, 2 - load meter, 3 - deformation meter, 4 - attachment, 5 - mixture, 6 - measuring jar.

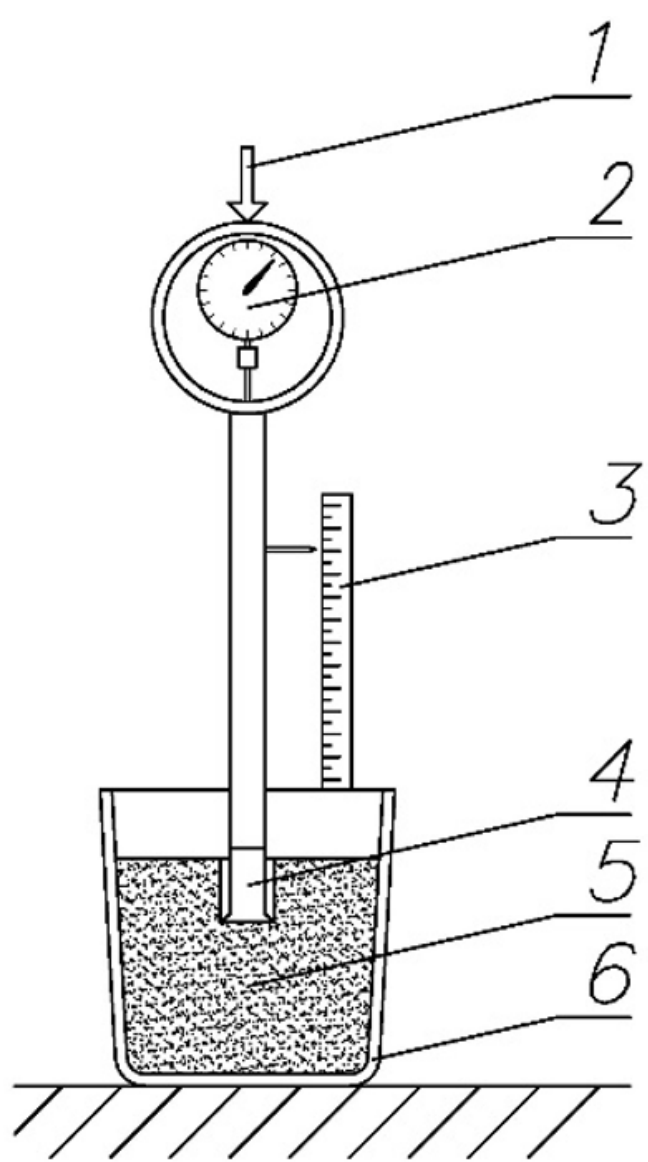

Fig. 8. Measurement scheme.

Figure 9 shows a sample of mixture measurement.



Fig. 9. Experiment. 


\section{Results}

Experimental research allowed one to obtain new data. Each measurement was based on 50-80 points depending on the soil (mixture) hardness. Each curve was obtained basing on 5 measurements on average. A sample of the data obtained for one measurement is shown in Figure 10. Y-axis represents resistance force (deformation indicator positions), while $\mathrm{X}$-axis represents deformation (soil penetration).

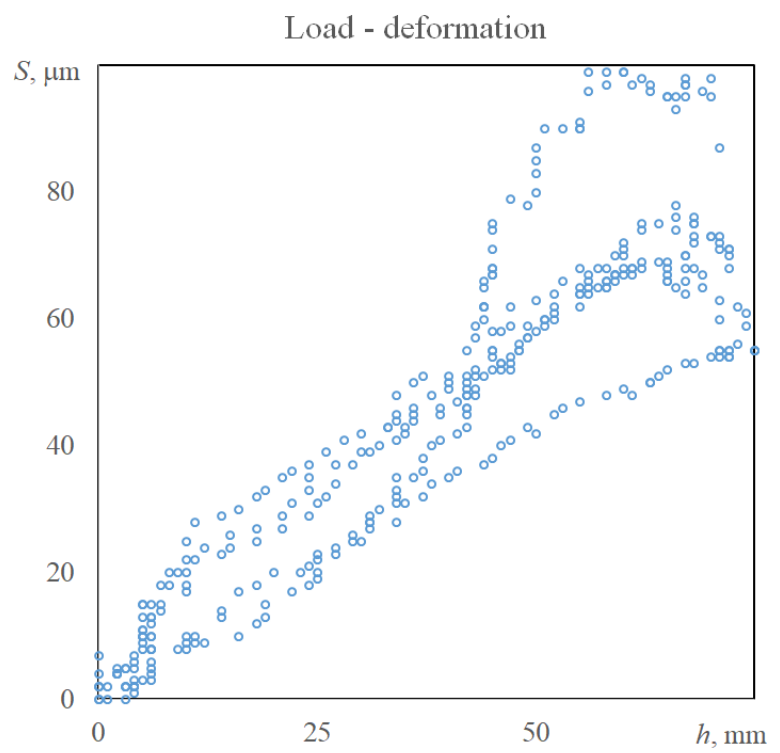

Fig. 10. A sample of per-unit load-deformation measurements.

The data obtained shows that experimental research conforms to the theory. Figure 11 presents average values for 5 types of mixtures.

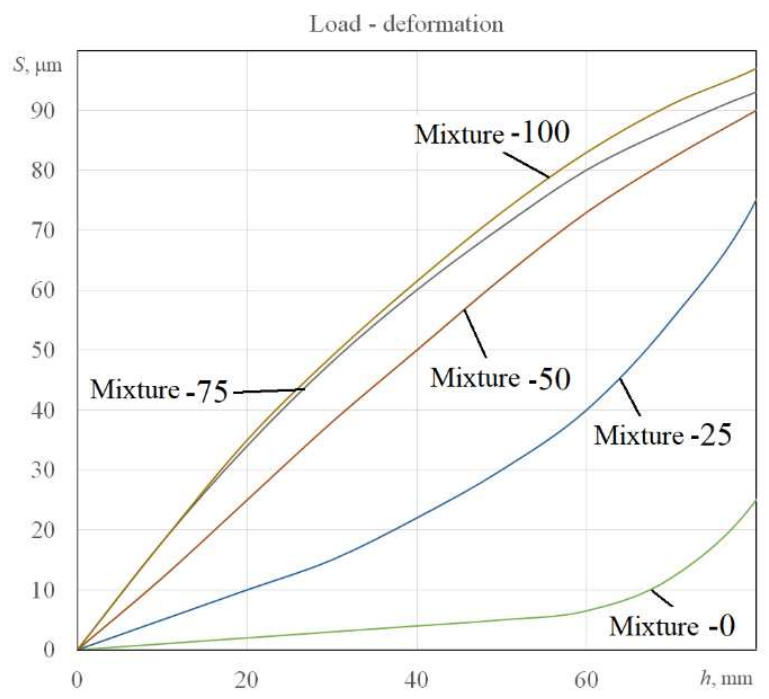

Fig. 11. A sample of per-unit load-deformation measurements

The $\mathrm{X}$-axis demonstrates soil penetration, while the $\mathrm{Y}$ axis displays dynamometer deformation, which will be further used to evaluate the force in the contact area, and basic soil parameters for the calculations.

Analysis of the graphs obtained in Figures 2 and 5 shows that the studies carried out confirm the theoretical model of Professor V.V. Belyakov. Figure 12 shows that the nature of the theoretical and experimental curves is the same.

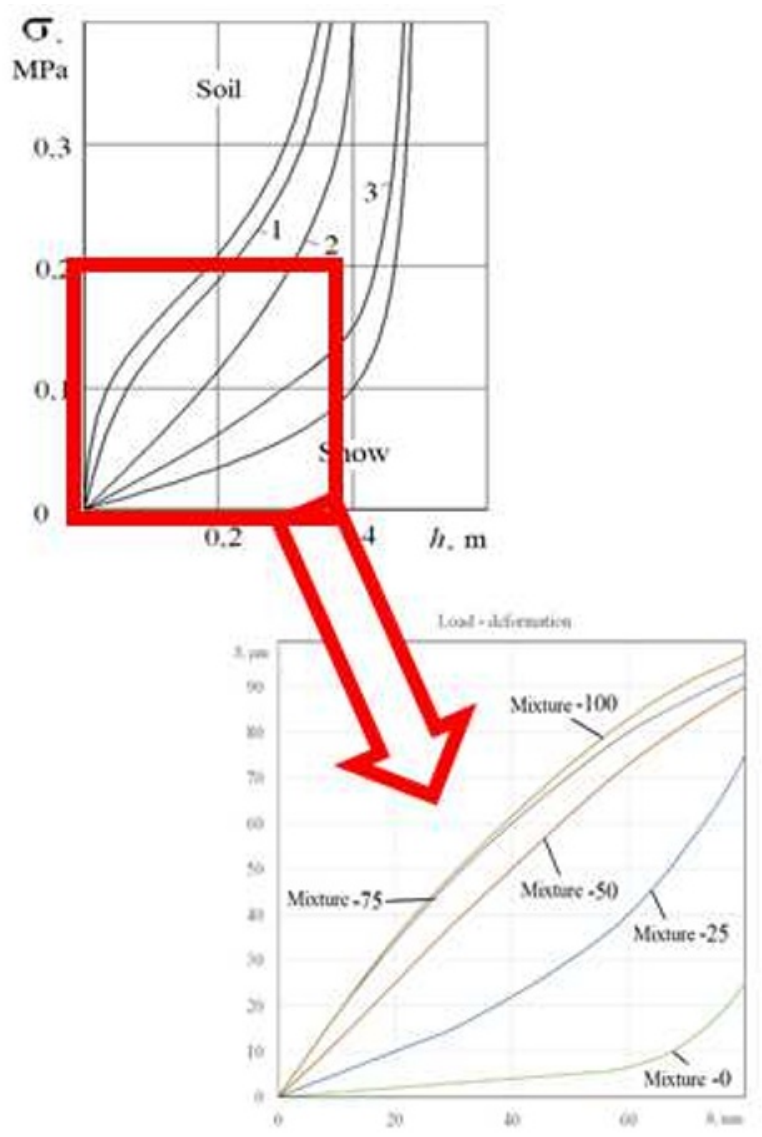

Fig. 12. Theoretical and experimental curves

Analytical dependencies for calculating the studied parameters look as follows:

- penetration force $P=k_{S} S$,

$$
-\operatorname{load} q=k_{i} P
$$

where $k_{S}, k_{i}$,- empirical coefficients.

The form of the graphs showed that the Goryachkin Letoshnev dependence can be used to describe the loaddeformation curve for sand [12-14]:

$$
q=c h^{n}
$$

where $\mathrm{c}$ and $n$ - soil constants.

For snow, the dependence from the «Nizhny Novgorod Scientific and Practical School of Transport Snow Science» will be valid $[15,16]$ :

$$
q=\gamma h\left[1-h h_{\max }^{-1}\right]^{-1},
$$

where $q$ - load on the stamp, $h$ - deformation, $\gamma-$ coefficient of initial stiffness of snow, which characterizes the resistivity of snow to compression, is the coefficient of stiffness at the initial stage of deformation; $\quad h_{\max }=h_{\max }(H) \quad-\quad$ coefficient characterizing the amount of snow deformation at pressures corresponding to maximum compaction depends on $H$ - height of snow cover. In more detail, the 
parameters included in dependence (4) are presented in $[15,16]$

The most common case that combines dependences (3) and (4) is the dependence proposed by [17]:

$$
q=c_{1}(H) h^{n_{1}(H)}
$$

where $c_{1}(H)=k_{1} e^{-k_{2} h_{\max }(H)}+\gamma, n_{1}(H)=a_{1} H+b_{1}$, $a_{1}=-a_{11} \rho+b_{11}, a_{11}, b_{11}, b_{1}, k_{1}, k_{2}$ - empirical coefficients, $\rho$ - snow density.

In the general case, the dependence for determining "load-deformation" can be represented as:

$$
q=K_{\mathrm{cr}} q_{\mathrm{c}}(h)+K_{\mathrm{rc}} q_{\mathrm{\Gamma}}(h),
$$

where $q_{\mathrm{c}}(h)$ and $q_{\Gamma}(h)$ - dependencies (3) and (4 or 5), $K_{\mathrm{c \Gamma}}, K_{\mathrm{c \Gamma}}$ - coefficients taking into account the influence of snow and soil components, depending on the concentration of each of the components $K_{\mathrm{c \Gamma}}=K_{\mathrm{c \Gamma}}\left(C_{c}\right)$, $K_{\text {гс }}=K_{\text {гс }}\left(C_{\Gamma}\right), C_{c}+C_{\Gamma}=1($ see Table 2$)$.

Table 2. Parameters of snow-sand mixtures.

\begin{tabular}{|c|c|c|c|}
\hline Title & $\begin{array}{c}\text { Snow to } \\
\text { sand ratio }\end{array}$ & Coeff. $\boldsymbol{C}_{\boldsymbol{c}}$ & Coeff. $\boldsymbol{C}_{\Gamma}$ \\
\hline Mixture-0 & $1 / 0$ & 1 & 0 \\
\hline Mixture-25 & $3 / 1$ & 0.75 & 0.25 \\
\hline Mixture-50 & $1 / 1$ & 0.5 & 0.5 \\
\hline Mixture-75 & $1 / 3$ & 0.25 & 0.75 \\
\hline Mixture-100 & $0 / 1$ & 0 & 1 \\
\hline
\end{tabular}

Experimental studies have shown that the nature of the support surface has a significant effect on the deformation of mixes. In this case, the undisturbed and destroyed support surface is deformed in different ways, depending on the percentage composition of snow and sand. For the measurements, it was found that for «mixed- 0 » the difference is up to 5 times, for «mixed$25 »-2$ times, for «mixed-50»- 3 times, for «mixed-75» - 2 times, for «Mixed-100»- 1.25 times. Figure 13 shows an example of how the «load-deformation» relationship changes for an undisturbed and destroyed support surface for a «mixed-75».

Thus, dependencies were obtained for calculating «load-deformation» for snow-sand mixtures. In the future, work will be carried out to clarify the parameters of the influence of the snow and soil components included in dependence (4).

It is also necessary to know how the ratio of snow and sand in the mixture affects the traction of the mover with the road.



Fig. 13. Theoretical and experimental curves

The dependences for calculating the resistance and friction forces are determined based on the stresses arising in the contact zone of the mover with the road, with subsequent integration over the contact area:

$$
\begin{gathered}
F_{R}=b \int_{0}^{h_{\Gamma}} q(h) d h, \\
F_{F}=b \int_{A} \tau d h A,
\end{gathered}
$$

where $b, h_{\Gamma}$ - track width and depth, $A$ - contact area of the mover with the road $[12,18,19]$.

Design schemes similar to studies (1 and 2), for MRC with tracked-modular (see Figure 1) and wheeled (see Figure 2) mover are shown in Figure 14.
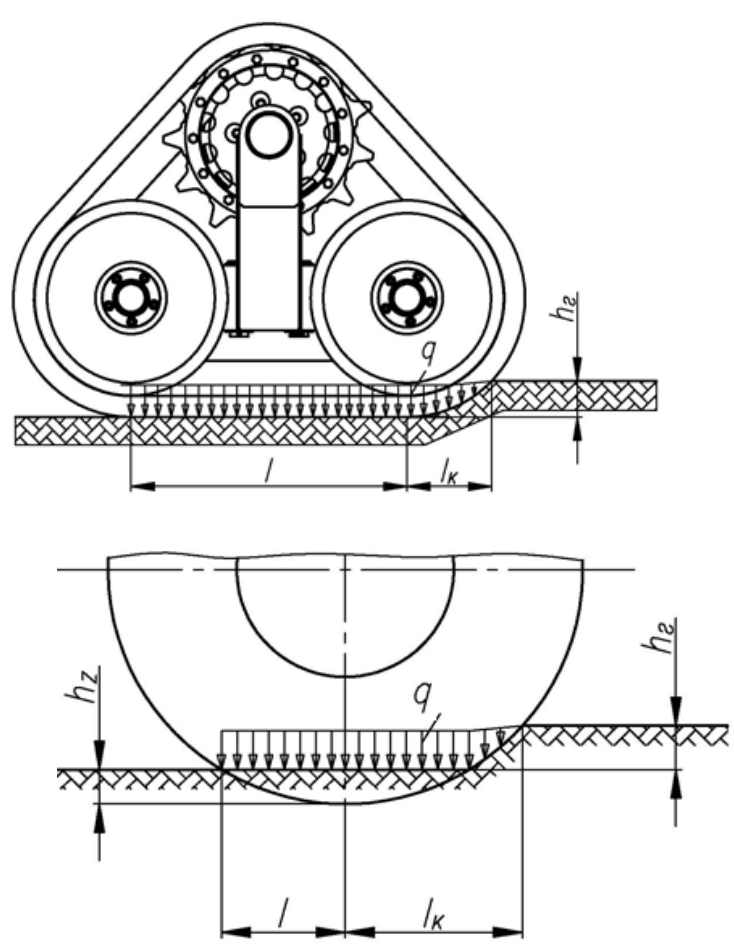

Fig. 14. Design schemes for the interaction of the trackedmodular and wheeled mover with the ground 


\section{Conclusions and future work}

This study allowed one to establish basic road-and-soil conditions for MRC mobility. Mixed surfaces present a lot of research opportunities. An experimental method has been developed to create a load-deformation curve, the preparation of snow-sand mixtures for the experiment to obtain the curve «load - deformation».

Samples of the data obtained as part of the research are provided.

Dependencies for calculating the deformation of sand and snow are given. A new dependence is proposed for calculating the parameters of snow-sand mixtures.

The research shows that frozen soil has a considerable impact on the penetration resistance force. Depending on the mixture type, penetration resistance values for an undisturbed road and soil surface several times more than for the surface exposed to an operating mover or a utility vehicle.

Schemes and dependencies are given for calculating the forces of resistance and friction for tracked-modular and wheeled propellers.

All data will be further processed, and mathematical functions will be obtained to describe the deformation process of the mixed surface. Also, simulation will be performed to evaluate the MRC mobility on the road and soil surfaces.

\section{Acknowledgments}

The results of the given study have been obtained with financial support of the grants of the President of the Russian Federation allocated to young researchers with doctor's degree no. MD-226.2020.8.

\section{References}

1. D.M. Barber, J.P. Mills, Proceedings of 5th International Symposium on Mobile Mapping Technology, Pradua, Italy. (2007)

2. A. Bio, et al., Journal of Integrated Coastal Zone Management. 15-1, 47 - 63, (2015)

3. D. Didier, et al., J. Mar. Sci. Eng. 3, 560 - 590. (2015).

4. A. Incoul, et al., INGEO 2014: 6th international conference on engineering surveying, Prague, Czech Republic, 87 - 92 (2014).

5. J. Kramer, and G. Hunter, Photogrammetric Week '07, 215 - 225. 2007.

6. A. Kurkin et al., Twelfth international conference on the Mediterranean coastal environment (MEDCOAST 15). 1 - 2, 933-943, (2015).

7. A. Zaytsev, et al., Science of Tsunami Hazards, 36(1), 1-12, (2017).

8. V. Makarov, et al., 19th International and 14th European-African Regional Conference of the ISTVS (2017).

9. A. Belyaev, et al., The 6th International Conference on Vehicle Technology and
Intelligent Transport Systems (VEHITS 2020). 567-572 DOI:10.5220/0009794705670572

10. S.M. Marokhin Prediction of the mobility characteristics of a special vehicle equipped with active safety systems. $\mathrm{PhD}$ thesis, Moscow, (2005).

11. B.A. Safonov, Automation of control of differential lock clutches in the transmission of a multi-axle wheeled vehicle. $\mathrm{PhD}$ thesis. Moscow. (2017).

12. Ya.S. Ageykin, N.S. Volskaya, Theory of the vehicle. MGIU, Moscow, (2008).

13. M. Bekker, 1960 Theory of land locomolion. (University of Michigan, Press)

14. J.Y. Wong Terramechanics and Off-Road Vehicle Engineering. (Elsevier, 2010)

15. L.V. Barakhtanov et al., Snowmobile vehicles. (Gorky. Volga-Viatskoe Publishers, 1986)

16. V.A. Maligin The study of snow deformation under the influence of caterpillar mover and rationale for choice of size of snow vehicle tracks. Ph.D. thesis, GPI, 1971.

17. S.E. Manyanin Increasing the cross-country ability of wheeled and tracked vehicles on snow by scientifically grounded choice of the design parameters of the movers, (Nizhny Novgorod, 2019).

18. Ya.S. Ageykin, N.S. Volskaya, Dynamics of the wheeled vehicle when driving on an uneven ground surface. (MGIU, Moscow, 2003).

19. Ya.S. Ageykin et al., Passability of vehicles. (MGIU, Moscow, 2010) 